\title{
ANTI-LISTERIAL EFFECT OF SELECTED ESSENTIAL OILS AND THYMOL
}

\author{
ERika-Beáta Kerekes, ${ }^{1}$ * Anita VidÁcs, ${ }^{1}$ Julianna Jenei TÖröK, ${ }^{3}$ Csilla GömöRi, ${ }^{1}$ \\ Tamás Petkovits, ${ }^{1}$ Muthusamy Chandrasekaran, ${ }^{2}$ Shine Kadaikunnan, ${ }^{2}$ \\ NaiYf S. AlharbI, ${ }^{2}$ Csaba VÁGVÖLGyi ${ }^{1}$ and Judit KrisCH ${ }^{3}$ \\ ${ }^{1}$ Department of Microbiology, Faculty of Science and Informatics, University of Szeged, 6726 Szeged, \\ Közép fasor 52., Hungary \\ 2Department of Botany and Microbiology, College of Science, King Saud University, \\ Riyadh-11451, Kingdom of Saudi Arabia \\ ${ }^{3}$ Institute of Food Engineering, Faculty of Engineering, University of Szeged, \\ 6722 Szeged, Mars tér 7., Hungary
}

(Received: January 20, 2016; accepted: February 5, 2016)

\begin{abstract}
The anti-listerial effect of marjoram, thyme essential oils (EOs) and thymol on Listeria monocytogenes inoculated chicken breast fillets was investigated. Before inoculation the fillets were pretreated by washing or not under running tap water. Inoculated samples were kept at $6{ }^{\circ} \mathrm{C}$ for $24 \mathrm{~h}$ to allow the growth of L. monocytogenes. After this, the fillets were put in marinating solutions containing salt (5\%) and EOs or thymol in MIC/2 concentration established in vitro. Total germ count (TGC) and L. monocytogenes count was monitored on the meat surface and in the marinating solutions following 24 and $48 \mathrm{~h}$ storage at $6{ }^{\circ} \mathrm{C}$. Thyme and thymol reduced significantly Listeria cell count (1-3 log CFU) in both samples. They also gave good flavour to the fried meat. The doses of EOs used were optimal for antimicrobial efficiency and had a pleasant flavour effect. Washing was not efficient in reducing total germ count.
\end{abstract}

Keywords: Listeria - essential oils - chicken meat - sensory evaluation

\section{INTRODUCTION}

Raw poultry meat products have frequently been found to be contaminated with pathogenic microorganisms which can cause life threatening diseases [12]. Listeria monocytogenes is one of the most important food-borne pathogens occurring in wide range of foods such as milk, meat products, fish and seafood [15]. The bacterium is capable of growing at refrigeration temperatures, low $\mathrm{pH}$ and in the presence of high salt concentrations making it difficult to control [7]. Immune compromised patients, pregnant women and the elderly are the most sensitive for Listeria infections. The ability of this bacterium to adapt efficiently to different environments by forming resistant biofilms on different surfaces makes the problem even more serious. These biofilms could be formed on various equipments and food handling surfaces used in the food industry [2]. The Listeria may persist in food plants for months and up to several years [18]. It has been demonstrated that the rapid adhesion of this bacterium to a surface, combined with biotransfer potential throughout the biofilm formation

*Corresponding author; e-mail address: kerekeserika88@gmail.com 
stages, makes L. monocytogenes a potential risk for the food industry; cells can easily be transferred to food products during processing [4]. Biofilm formation and growth can continue on the surface of foods leading to outbreaks of listeriosis. Because biofilms easily create resistance against a lot of commonly used antimicrobials and preservatives the need for developing new eradication strategies is emerging [8].

There is a growing interest in using essential oils (EOs) as natural preservatives against food spoilage- and food-borne pathogens [3]. EOs with phenolic compounds like thyme, oregano, mint and others are known to possess good antimicrobial properties. They can control the growth of pathogens and can extend shelf life of food products [3,12].

The food industry primarily uses EOs as flavourings. Their use as food preservatives requires further knowledge about their mode of action and the effect of the food matrix components on their antimicrobial properties $[1,9]$. It is known that EOs cause increased membrane permeability due to damage in membrane integrity, which affects $\mathrm{pH}$ homeostasis and equilibrium of inorganic ions [9]. Several studies are published regarding the effect of EOs on food borne pathogens like Listeria. Targeting surface colonization rather than bacterial fitness seems to be a good approach, because the selective pressure is lower and may lead to fewer resistant strains [16]. In a recent study, raw chicken fillets were inoculated with $L$. monocytogenes and the effects of chitosan (a commonly used preservative) and oregano EO were tested for the extension of shelf life of the meat. Both compounds (especially chitosan) had a significant antibacterial and preservative effect. When these antimicrobials used in combination they extended the shelf life of the chicken fillets with six days [12].

The latest guidelines of United States Department of Agriculture (USDA) and Food Safety Authority (FSA) [6, 20] do not recommend washing of the poultry meat to avoid spreading of Campylobacter and other possible pathogens. However, in households washing of the poultry meat before use is a common practice. The aim of the present study was to investigate the anti-listerial effect of marjoram, thyme EOs and thymol on washed and unwashed chicken breast fillets.

\section{MATERIALS AND METHODS}

\section{Bacterial strain}

The Gram-positive bacterium Listeria monocytogenes (strain code: NCAIM B01934) was obtained from the National Collection of Agricultural and Industrial Microorganism (Corvinus University, Budapest, Hungary) and deposited at $-80{ }^{\circ} \mathrm{C}$ in the Szeged Microbiological Collection (strain code: SZMC 21307) maintained by the Department of Microbiology, University of Szeged (Szeged, Hungary). Cultivations were carried on Palcam Selective Agar (Lab M, UK) at $37^{\circ} \mathrm{C}$. 


\section{Essential oils}

Based on the results of previous experiments $[11,17]$ marjoram (Origanum majorana) and thyme (Thymus vulgaris) EOs were involved in this study. They were purchased from Aromax Natural Products Ltd. (Budapest, Hungary). Thymol (the major component of thyme EO) was obtained from Sigma-Aldrich (Hungary). The compositions of the oils were determined by GC-MS (Agilent 6850 Series II; MS: 5975C VL MSD; Agilent Technologies, Palo Alto, CA, USA) using an Agilent 19091S-433E colonna at the laboratory of Aromax Natural Products Ltd. (Budapest, Hungary).

\section{In vitro determination of minimal inhibitory concentration (MIC)}

For determination of MIC values the bacterium was grown in Tryptic Soya Broth (TSB; peptone from casein: $17 \mathrm{~g}$ (Merck, Hungary), peptone from soy meal: $3 \mathrm{~g}$ (Oxoid, UK), D(+)-glucose: 2.5 g (VWR, Hungary), NaCl: 5 g (VWR, Hungary), $\mathrm{K}_{2} \mathrm{HPO}_{4} 2.5 \mathrm{~g}$ for $1000 \mathrm{~mL}$ ) at $37^{\circ} \mathrm{C}$. The dilutions of the EOs were made in liquid culture media in combination with Tween $40(1 \%)$. Thymol was dissolved in ethanol before it was added to liquid culture media. One hundred $\mu$ lof 24-h-old cell suspension $\left(10^{6} \mathrm{CFU} / \mathrm{mL}\right)$ in liquid culture medium was added to the wells of a 96 -well microtiter plate, followed by $100 \mu \mathrm{l}$ of the diluted EO or the component. Positive controls contained the inoculated growth medium without any EOs or components and negative controls contained EOs or thymol in sterile medium. After $24 \mathrm{~h}$ incubation at $37{ }^{\circ} \mathrm{C}$, absorbance was measured at $600 \mathrm{~nm}$ (SPECTROstar Nano spectrophotometer, BMG Labtech, Germany). Decrease of the absorbance of the treated samples to $10 \%$ or lower of the positive control was considered as the MIC value. Measurements were made in triplicates. Bacteriostatic or bacteriocidic character of inhibition was determined by plating $100 \mu \mathrm{L}$ suspensions from MIC or higher concentrations onto PALCAM selective medium. The MIC/2 values of these oils and thymol were used for marinating the chicken breast fillets.

\section{Pretreatment inoculation and marinating of chicken breast fillets}

Fresh, skinless chicken breast fillets were purchased from a local market (Szeged, Hungary). They were cut aseptically in $1 \mathrm{~cm}$ thick $5 \times 5 \mathrm{~cm}$ cubes. The two sample groups were unwashed and washed meat cubes where the washing was made with running tap water. After pretreatment, the cubes were soaked with sterile paper kitchen towel and placed in sterile polystyrene boxes. Boxes were sterilized by soaking with chlorinated water $(1000 \mathrm{ppm})$ followed by illumination with UV light (30 $\mathrm{min}$ ) in a biological safety cabinet. Chicken breast cubes were inoculated with bacterial suspension prepared in sterile distilled water from a 24-h-old L. monocy- 
togenes culture. One hundred $\mu \mathrm{L}$ was pipetted onto the surface of each cube and evenly distributed with a bent glass spreader. Inoculating suspension contained approximately $10^{4} \mathrm{CFU}$ corresponding to $10^{2} \mathrm{CFUs} / \mathrm{cm}^{2}$. Inoculum size was adjusted according to the natural Listeria counts determined for raw poultry foodstuffs [14] and the European legislation limit (Regulation (EC) No 2073/2005). Samples were kept for $24 \mathrm{~h}$ at refrigerated conditions $\left(6 \pm 1^{\circ} \mathrm{C}\right)$ for listerial growth. Three marinating solutions were prepared containing $5 \%(\mathrm{w} / \mathrm{v})$ salt and one of the EOs or thymol in $\mathrm{MIC} / 2$ concentrations. Thymol (purchased in powder form) was first dissolved in $500 \mu \mathrm{L}$ ethanol $(96 \%, \mathrm{v} / \mathrm{v})$. Thymol solution or the essential oils were directly pipetted onto the solid salt and then they were dissolved in sterile distilled water. Boxes with the two different (washed and unwashed) chicken samples were filled with these marinating solutions covering the whole surface of the meat cubes. Control samples contained only $5 \%$ salt without any other seasoning. Samples were incubated for 24 and $48 \mathrm{~h}$ at refrigerated conditions $\left(6 \pm 1^{\circ} \mathrm{C}\right)$.

\section{Microbiological analysis of chicken breast fillets}

For determination of the natural microbial counts of fresh chicken fillets meat surfaces were sampled with sterile culture swabs, which were placed in test tubes containing $9 \mathrm{~mL}$ of sterile peptone water. The same sampling method was used after treatments with EOs. Marinating solutions were analyzed by adding $1 \mathrm{ml}$ of sample to $9 \mathrm{~mL}$ peptone water. Total germ count (TGC) was determined using Plate Count Agar (Merck, Hungary). Number of coliform bacteria were determined using Brilliant Green Broth. Presence of Escherichia coli was determined by inoculating $1 \mathrm{~mL}$ from the positive tubes into tryptophan broth to detect indol production. The presence of Salmonella was established after pre-enrichment carried out by adding $25 \mathrm{~g}$ of meat to $225 \mathrm{~mL}$ peptone water. Staphylococcus aureus was investigated on Baird Parker Agar (Merck, Hungary) and presence of Listeria was determined on Palcam Selective Agar (Merck, Hungary).

\section{Sensory evaluation}

Marinated, non-inoculated meat cubes were fried in sunflower oil. A panel of six untrained judges was asked to evaluate odour and taste intensities of the fried meat. The reference sample was kept in a solution containing only $5 \%$ salt. Odour and taste acceptability was estimated using a hedonic scale ranging from 5 to 1 with 5 corresponding to the most-liked and 1 corresponding to the least-liked sample. The limit of acceptability was established at 3 . Sensory evaluations were repeated twice with different chicken samples. 


\section{Statistical analysis}

Microbiological data were transformed into logarithms of the number of colony forming units $\left(\mathrm{CFU} / \mathrm{cm}^{2}\right)$ and were subjected to one-way analysis of variance (ANOVA). Statistical analysis was conducted using R Works 2.8.0. Significance was considered at $\mathrm{P}<0.05$.

\section{RESULTS}

\section{Composition and in vitro MIC values of EOs}

The main components of marjoram and thyme EOs are indicated in Table 1. Marjoram had terpinen-4-ol (terpene alcohol) as main component with considerable amounts of $\gamma$-terpinene and cis-sabinene hydrate. Thyme EO had thymol (phenolic compound) as major component and a considerable amount of its precursor $\mathrm{p}$-cymene. MIC values of EOs against L. monocytogenes were $3.5 \mathrm{mg} / \mathrm{mL}$ for marjoram and $2 \mathrm{mg} / \mathrm{mL}$ for thyme. The best inhibitory effect was achieved with thymol $(0.5 \mathrm{mg} / \mathrm{mL})$.

Table 1

Chemical composition of essential oils (\%), as given by the producer

\begin{tabular}{|l|c|c|}
\hline \multicolumn{1}{|c|}{ Components (\%) } & $\begin{array}{c}\text { Marjoram } \\
\text { Origanum majorana }\end{array}$ & $\begin{array}{c}\text { Thyme } \\
\text { Thymus vulgaris }\end{array}$ \\
\hline p-cymene & - & 31.7 \\
\hline Terpinen-4-ol & 33.5 & - \\
\hline Thymol & - & 51.8 \\
\hline$\beta$-phellandrene & 8 & - \\
\hline$\gamma$-terpinene & 19.5 & 6.2 \\
\hline
\end{tabular}

- Not detected.

\section{Microbiological load of chicken fillets before and after inoculation}

The initial TGC of the fresh chicken meat purchased from the market was $4.3 \log$ $\mathrm{CFU} / \mathrm{cm}^{2}$. Coliform numbers were less than $10 \mathrm{CFU} / \mathrm{cm}^{2}$ and no Staphylococcus, Salmonella or Listeria was detected. This means that the fillets met the demands of the European and Hungarian food safety standards. After 24-h pre-incubation with Listeria, unwashed and washed cubes had 2.9 and $3.4 \log \mathrm{CFU} / \mathrm{cm}^{2}$, respectively. E. coli numbers were less than $10 \mathrm{CFU} / \mathrm{cm}^{2}$ and neither Staphylococcus nor Salmonella could be detected. 


\section{Microbiological changes of inoculated chicken breast fillets after marinating}

Changes in TGC and Listeria counts on unwashed and washed meat cubes are presented in Figures 1 and 2. After 24-h storage significant reduction of TGC was achieved only with thymol $(2.5 \log$ reduction, $\mathrm{P}<0.001)$. Listeria counts dropped considerably following treatment with thyme EO ( $0.45 \log$ reduction, $\mathrm{P}<0.001)$. After $48 \mathrm{~h}$, the TGC values of the control sample increased to $5.15 \log \mathrm{CFU} / \mathrm{cm}^{2}$, but in

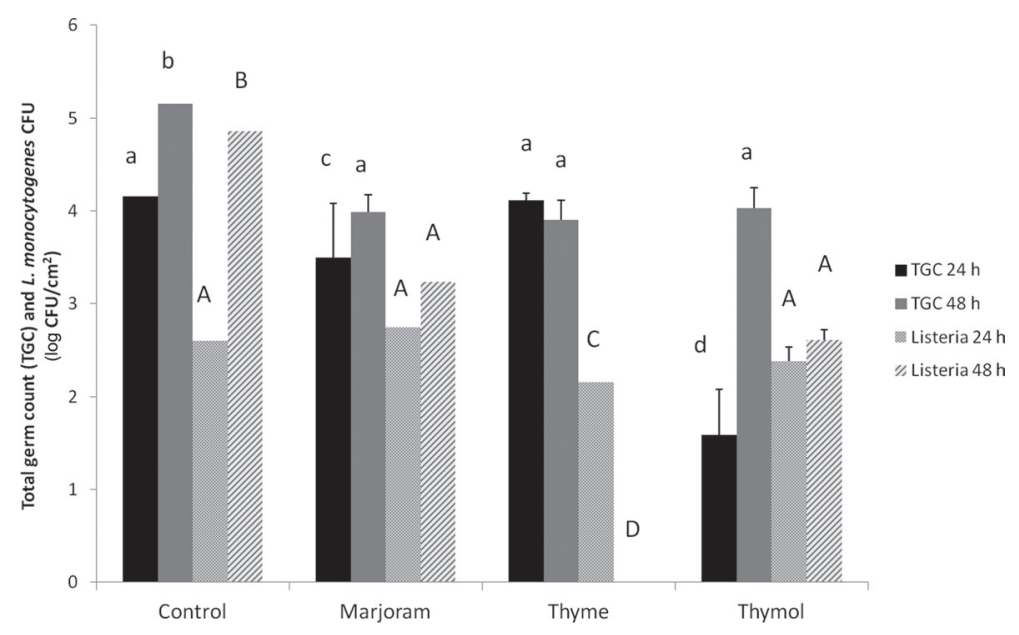

Fig. 1. Total germ counts (TGC) and Listeria CFU after marinating of the unwashed samples. Lower cases show comparison between EOs and the control sample in case of TGC and upper cases, comparison between L. monocytogenes counts

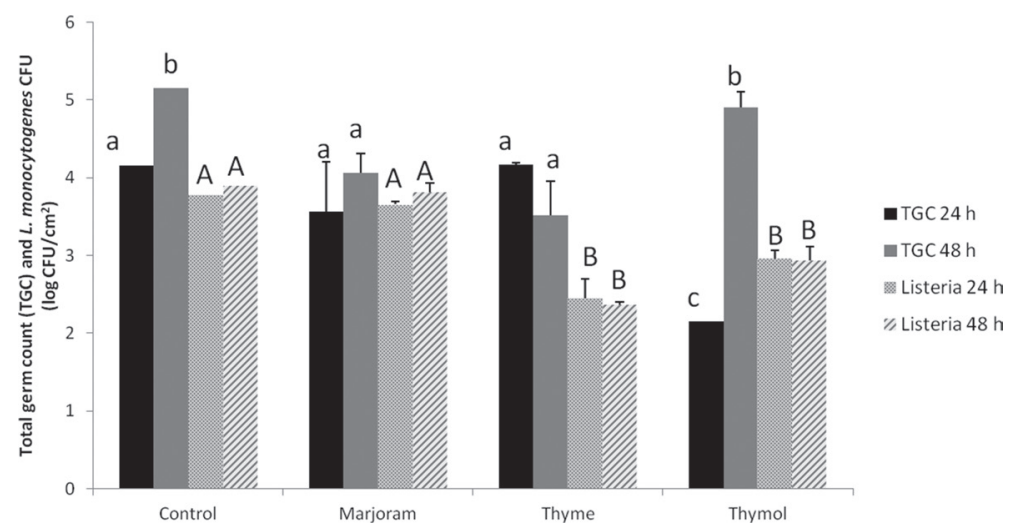

Fig. 2. Total germ counts (TGC) and Listeria CFU after marinating of the samples washed with water. Lower cases show comparison between EOs and the control sample in case of TGC and upper cases, comparison between L. monocytogenes counts 
treated samples TGC remained at the level of the $24 \mathrm{~h}$ values. Compared to the control $\left(4.8 \log \mathrm{CFU} / \mathrm{cm}^{2}\right)$ Listeria counts were reduced with $1.6 \mathrm{log}$ after marinating with marjoram and 2 log after thymol. Thyme EO completely reduced CFU (Fig. 1).

For washed samples thymol was the best inhibitor reducing TGC with 2 logs after $24 \mathrm{~h}$. Listeria CFU was reduced with approximately $1 \log (\mathrm{P}<0.001)$ after marinating with thyme and thymol (thyme was more effective). After $48 \mathrm{~h} \mathrm{TGC}$ was reduced by marjoram and thyme $(\mathrm{P}<0.05)$. Thymol was not efficient in this case but it exhibited a good anti-listerial effect along with thyme $(\mathrm{P}<0.001)$ (Fig. 2).

\section{Microbiological changes in the marinating solutions of inoculated chicken breast fillets}

Results of the marinating solutions are presented in Figures 3 and 4. TGC values of the unwashed samples stored for $24 \mathrm{~h}$ were reduced by all marinating agents. A 0.6 , 2.5 and $3 \log$ reduction was obtained after marjoram $(\mathrm{P}<0.05)$, thyme $(\mathrm{P}=0.003)$ and thymol $(\mathrm{P}<0.001)$ treatments, respectively. Thymol reduced Listeria CFU with 2 logs while the other two EOs completely inhibited growth. Marjoram was not effective against TGC in the 48-h samples $(\mathrm{P}>0.05)$ but thyme and thymol reduced cell counts significantly (1.7 and $2 \mathrm{log}$ reductions). No listerial growth could be detected in solutions with marjoram and thyme EOs while thymol resulted in a $2 \log$ reduction of cell count (Fig. 3).

Washed samples stored for $24 \mathrm{~h}$ showed 1, 6 and 5 logs reduction after marinating with marjoram, thyme and thymol, respectively. Listeria could not be detected in either of the solutions. Only thymol was effective in reducing TGC values after $48 \mathrm{~h}$

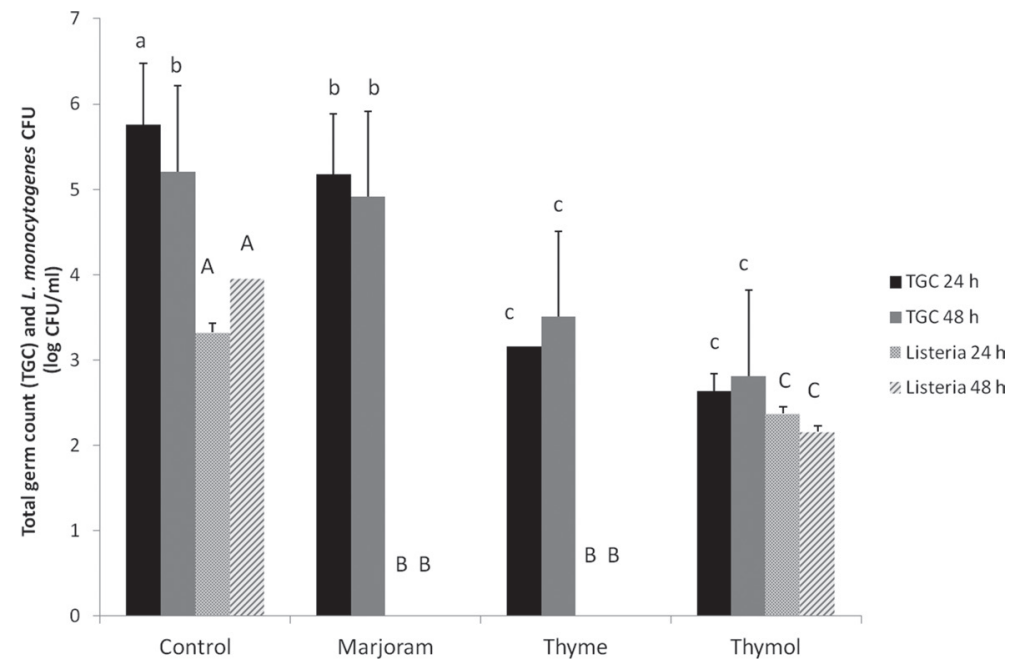

Fig. 3. Total germ counts (TGC) and Listeria CFU after marinating in the marinating solutions of the unwashed samples. Lower cases show comparison between EOs and the control sample in case of TGC and upper cases, comparison between L. monocytogenes counts 


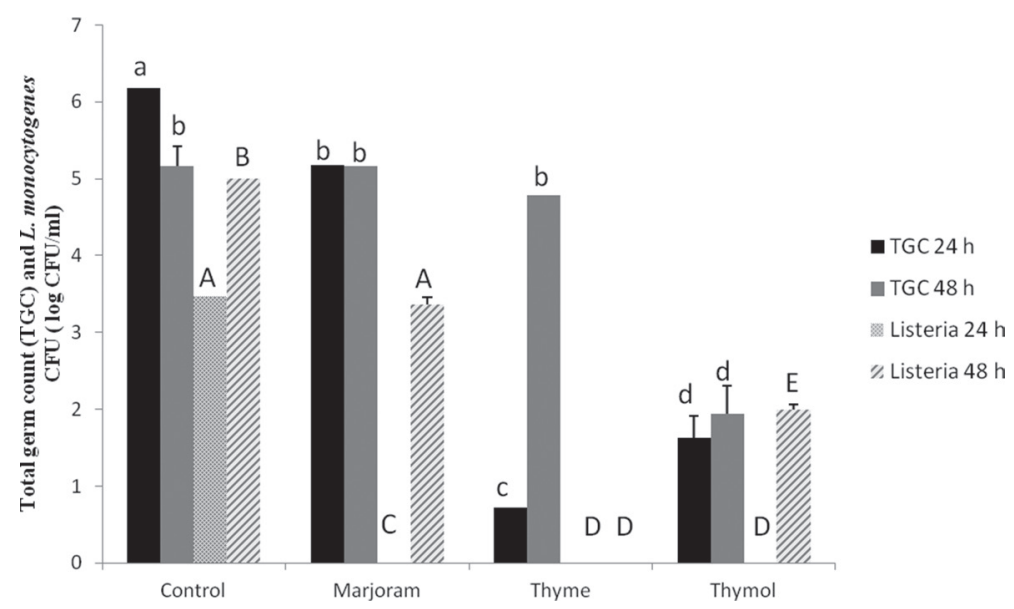

Fig. 4. Total germ counts (TGC) and Listeria CFU after marinating in the marinating solutions of the washed samples. Lower cases show comparison between EOs and the control sample in case of TGC and upper cases, comparison between L. monocytogenes counts

storage ( 3 logs) and Listeria was reduced in all marinating solutions; thyme being the most efficient EO (Fig. 4).

\section{Sensory evaluation of the marinated chicken breast fillets}

In case of marjoram, sensory panelists rated the fillets with an average score of 3.4 for odour and 2 for taste. These results differed significantly from the control sample in both their odour $(\mathrm{P}=0.01)$ and taste $(\mathrm{P}<0.001)$. It was also stated that the meat

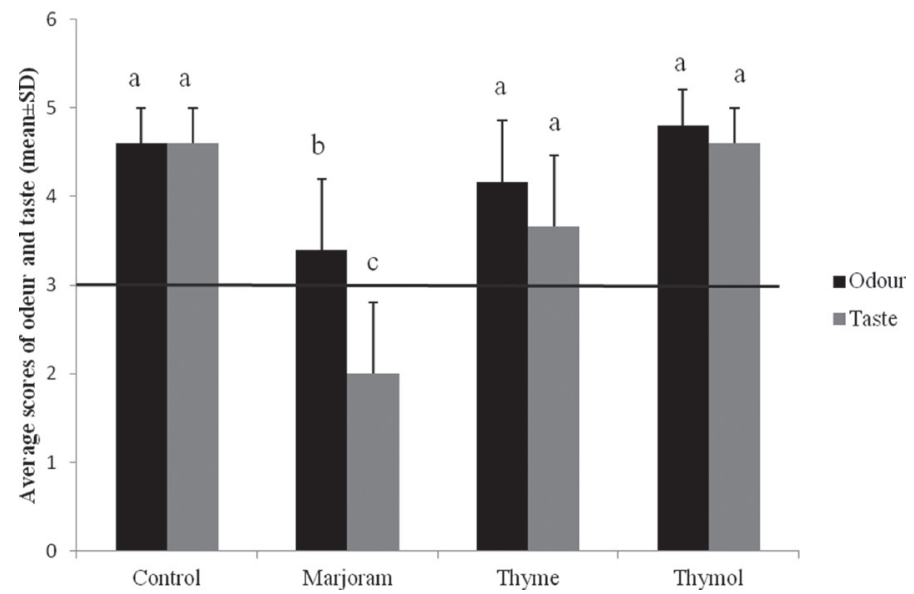

Fig. 5. Average scores of the sensory evaluation of chicken fillets after marination. Values are mean \pm SD and significant differences are marked with low cases. The limit of acceptability is marked by a black line 
had an unpleasant aftertaste. Thyme and thymol had similar acceptability to the control sample regarding odour and taste scoring between 3.6 and 4.8 for both parameters. In these cases panelists stated that the meat had a nice spicy taste which harmonized with the meat. For some of the panelists the meat samples were too salty (Fig. 5).

\section{DISCUSSION}

Food contamination is a serious public health problem that may be better controlled with the use of natural preservatives. EOs and thymol used in these experiments were chosen because these flavours are frequently used for seasoning the chicken meat. Marinating with MIC/2 values of marjoram $\mathrm{EO}$ gave an unpleasant aftertaste, furthermore, it had no significant effect in reducing neither TGC nor Listeria CFU. On the other hand, we could determine a dose of thyme EO which combines antimicrobial efficiency with a pleasant flavour $(1 \mathrm{mg} / \mathrm{mL}$ for thyme and $0.2 \mathrm{mg} / \mathrm{mL}$ for thymol). This shows that the use of EOs is limited and it is difficult (but not impossible) to find a concentration where both antimicrobial effect and pleasant flavour is combined.

Washing of the meat had apparently no effect on TGC counts. On the other hand listerial growth during the $24 \mathrm{~h}$ pre-incubation increased after washing. Explanation of this finding would require further studies. Though it was found earlier that psychrotrophic lactobacilli on the meat surface could have inhibitory activity against L. monocytogenes [5, 17], however, bacteria isolated from the meat surface in our study did not show any antagonism to Listeria.

Results show that in the marinating solutions TGC values were higher than on the surface of the meat. It is important to note that thyme and thymol inhibited growth in the marinade more effectively than on the meat surface. This result is in agreement with literature data stating that planktonic cells are more susceptible to inhibitors [10]. Washing poultry meat before use is discouraged by the authorities to avoid spreading of pathogens. Our study also proved that washing was not efficient in lowering TGC and pathogenic germ counts so there is no reason to wash the meat before further use.

The use of EOs as spices and preservatives at an industrial level requires detailed knowledge of their not-standardized chemical composition. Changes in their components occur because of environmental factors like temperature, humidity, harvest time, effect of soil properties, the maturation of the plant [21,22]. It is highly recommended to measure chemical compositions, antimicrobial effect and the interaction of EOs with the food matrix before adding them to food products.

According to our findings, thyme $\mathrm{EO}$ and thymol could keep L. monocytogenes and TGC counts low on marinated raw chicken fillets at proper refrigerated conditions without having negative effect on organoleptic properties. 


\section{ACKNOWLEDGEMENTS}

E. B. Kerekes thanks the National Talent Program for the accorded personal grant (Grant nr. NTPEFÖ-P-15-0435). The authors extend their sincere appreciation to the Deanship of Scientific Research at King Saud University for funding this Prolific Research Group (PRG-1437-36).

\section{REFERENCES}

1. Bakkali, F., Averbeck, S., Averbeck, D., Idaomar, M. (2008) Biological effects of essential oils - a review. Food Chem. Toxicol. 46, 446-475.

2. Beresford, M. R., Andrew, P. W., Shama, G. (2001) Listeria monocytogenes adheres to many materials found in food-processing environments. J Appl. Microbiol. 90, 1000-1005.

3. Burt, S. (2004) Essential oils: their antibacterial properties and potential applications in foods $-\mathrm{a}$ review. Int. J. Food Microbiol. 94, 223-253.

4. De Oliveira, M. M. M., Florisvaldo Brugnera, D., Das Graças Cardoso, M., Alves, E., Hilsdorf Piccoli, R. (2010) Biofilm formation by Listeria monocytogenes on stainless steel surface and biotransfer potential. Braz. J. Microbiol. 41, 97-106.

5. Farber, J. M., Peterkin, P. (1991) Listeria monocytogenes, a food-borne pathogen. Microbiol. Rev. 55, 476-511.

6. Food Standard Agency (2014) Don't wash raw chicken. Retrieved from https://www.food.gov.uk/ news-updates/campaigns/campylobacter/fsw-2014

7. Gandhi, M., Chikindas, M. L. (2007) Listeria: A foodborne pathogen that knows how to survive. Int. J. Food Microbiol. 113, 1-15.

8. Høiby, N., Bjarnsholt, T., Givskov, M., Molin, S., Ciofu, O. (2010). Antibiotic resistance of bacterial biofilms. Int. J. Antimicrob. Agents 35, 322-332.

9. Hyldgaard, M., Mygind, T., Meyer, R. L. (2012) Essential oils in food preservation: mode of action, synergies, and interactions with food matrix components. Front. Microbiol. 3, 12.

10. Johnson, L. R. (2007) Microcolony and biofilm formation as a survival strategy for bacteria. J. Theor Biol. 251, 24-34.

11. Kerekes, E.-B., Deák, É., Takó, M., Tserennadmid, R., Petkovits, T., Vágvölgyi, C., Krisch, J. (2013) Anti-biofilm forming and anti-quorum sensing activity of selected essential oils and their main components on food-related micro-organisms. J. Appl. Microbiol. 115, 933-942.

12. Khanjari, A., Karabagias, I. K., Kontominas, M. G. (2013) Combined effect of N,O-carboxymethyl chitosan and oregano essential oil to extend shelf life and control Listeria monocytogenes in raw chicken meat fillets. LWT-Food Sci. Technol. 53, 94-99.

13. Noriega, E., Shama, G., Laca, A., Díaz, M., Kong, M. G. (2011) Cold atmospheric gas plasma disinfection of chicken meat and chicken skin contaminated with Listeria innocua. Food Microbiol. 28 , 1293-300.

14. Mead, P. S., Dunne, E. F., Graves, L., Wiedmann, M., Patrick, M., Hunter, S., Salehi, E., Mostashari, F., Craig, A., Mshar, P., Bannerman, T., Sauders, B. D., Hayes, P., Dewitt, W., Sparling, P., Griffin, P., Morse, D., Slutsker, L., Swaminathan, B. (2006) Nationwide outbreak of listeriosis due to contaminated meat. Epidemiol. Infect. 134, 744-751.

15. Rasooli, I., Rezaei, M. B., Allameh, A. (2006) Ultrastructural studies on antimicrobial efficacy of thyme essential oils on Listeria monocytogenes. Int. J. Infect. Dis. 10, 236-241.

16. Rendueles, O., Ghigo, J.-M. (2012) Multi-species biofilms: how to avoid unfriendly neighbors. FEMS Microbiol. Rev. 36, 972-989.

17. Sakaridis, I., Soultos, N., Dovas, C. I., Papavergou, E., Ambrosiadis, I., Koidis, P. (2012) Lactic acid bacteria from chicken carcasses with inhibitory activity against Salmonella spp. and Listeria monocytogenes. Anaerobe 18, 62-66.

18. Tompkin, R. B. (2002). Control of Listeria monocytogenes in the food-processing environment. $J$ Food Prot. 65, 709-725. 
19. Tserennadmid, R., Takó, M., Galgóczy, L., Papp, T., Pesti, M., Vágvölgyi, C., Almássy, K., Krisch, J. (2011) Anti yeast activities of some essential oils in growth medium, fruit juices and milk. Int. J. Food Microbiol. 144, 480-486.

20. United States Department Of Agriculture (2013) Washing food: does it promote food safety? Retrieved from http:/www.fsis.usda.gov/wps/portal/fsis/topics/food-safety-education/get-answers/ food-safety-fact-sheets/safe-food-handling/washing-food-does-it-promote-food-safety/washing-food

21. Verma, R. S., Padalia, R. C., Chauhan, A. (2013) Introduction of Cymbopogon distans (Nees ex Steud.) Wats to the sub-tropical India: Evaluation of essential-oil yield and chemical composition during annual growth. Ind.Crop.Prod. 49, 858-863.

22. Verma, R. S., Padalia, R. C., Chauhan, A. (2014) Chemical composition variability of essential oil during ontogenesis of Daucus carota L. subsp. sativus (Hoffm.) Arcang. Ind.Crop.Prod. 52, 809-814. 